\title{
Indledning: Muslimer i transnationalitet / Transnational islam
}

\author{
Af Nils Bubandt, Maria Louw og Mikkel Rytter
}

Markante begivenheder i nyere tid såsom Rushdie-affæren, den 11. september og karrikaturkrisen har sat islam på den internationale dagsorden. Trods forudsigelser om religionernes mistede betydning og verdens af-fortryllelse synes religion at have fået ny kraft og vitalitet $\mathrm{i}$ en moderne global verden. Det er ikke længere alene relevant at forholde sig til globaliseringen af islam, men også til islam som en globaliseringsdynamik.

Alle fem artikler i dette temanummer operer på to niveauer. Dels tilvejebringer artiklerne empirisk viden om, og analytisk indsigt i, 'muslimer i transnationalitet': de viser, hvordan lokale religiøse praksisser og trosforestillinger knytter muslimer - med eller mod deres vilje - til forskelligartede fællesskaber på tværs af landegrænser. Dels giver artiklerne teoretiske perspektiver på 'transnational islam', i den forstand, at de alle på et mere overordnet plan afsøger og diskuterer religionens organisering, appel og plasticitet i en global verden. Vi vil diskutere de to analytiske niveauer lidt mere udførligt hver for sig.

Et fokus på 'muslimer i transnationalitet' tager afsæt i individer og grupper, der bekender sig til, og i varierende grad praktiserer, religionen islam. Deres liv er (ligesom alle andres) placeret i og formet af en lokal og national kontekst med sin egen unikke historie og sine egne unikke mulighedsbetingelser. På samme tid indgår de dog også i forbindelser og fællesskaber på tværs af disse grænser. Termen 'muslimer i transnationalitet' henviser derfor både til muslimer, der lever som del af en majoritet i lande hvor islam er den dominerende religion og derfra knytter forbindelser ud i verden, og til muslimer der qua en forhistorie som migranter eller flygtninge lever som minoriteter rundt om i verden.

Generelt fordrer et transnationalt perspektiv et opgør med den 'metodologiske nationalisme' (Beck 2002; Wimmer og Glick Schiller 2003), der, som en container, lader nationalstaten og dets samfund være ramme for en given analyse. I stedet er det blevet foreslået, at vi begriber vores studieobjekt som 'sociale felter'; en langt mere fleksibel betegnelse som rummer samspillet mellem lokale og globale niveauer og fænomener (Gluckman 2006: 20). Som direkte følge heraf kan 'transnationale 
sociale felter' defineres som: 'a set of multiple interlocking networks of social relationships through which ideas, practices and resources are unequally exchanged, organised and transformed' (Levitt og Glick Schiller 2004: 1009).

Ralph Grillo (2004) peger på tre modeller for, hvordan religiøse forestillinger og praksisser knytter praktiserende muslimer sammen i transnationale sociale felter.

1. Det kan ske bi-polært dvs. tilfælde hvor der er to destinationer involveret fx AlgerietFrankrig eller Danmark-Pakistan.

2. Det kan også ske cirkulært, dvs. at mennesker, kapital, ideer og objekter cirkuleres mellem tre eller flere destinationer.

3. Eller det kan henvise til den overnationale forestilling om den muslimske umma, et forestillet fællesskab der knytter muslimer sammen verden over (Grillo 2004: 865-866). Samlet tager et perspektiv på 'muslimer i transnationalitet' afsæt i, hvordan personer, familier og kollektiver konkret søger at leve og praktisere deres religiøse tro på deres egne måder indenfor de mulighedsbetingelser, som disse forskellige transnationale sociale felter giver.

Anderledes forholder det sig med perspektivet på 'transnational islam', der henviser til religionens udstrækning og vidtrækkende appel, dens globale organisering samt markante plasticitet. Det er blevet foreslået, at den iranske revolution i 1979 signallerede en ny slags 'globalitet', en verden hvor religion er en central aktør på den globale politiske scene (Berger 1999; Casanova 1994; Habermas 2002). I den forstand er religion blevet en global drivkraft: en proces som for både islam og kristendommens vedkommende er accelereret siden terroranslagene i New York og Washington 2001. Selvom dette er et kendt fænomen, har det kun langsomt ændret ved den akademiske debat om transnationalisme og globalisering, der fortsat fokuserer mere på økonomiske og teknologiske dimensioner end på 'spirituelle' former for globalisering, og derved risikerer at overse, hvor meget det økonomiske og det spirituelle reelt er knyttet sammen i verden i dag. Joel Robbins ser for eksempel spredningen af karismatisk kristendom som et af de mest succesfulde men også oversete eksempler på globalisering (Robbins 2004). Islam synes på samme måde at være globaliseret på en mere intens måde de senere år. Vi bør dog være opmærksomme på den 'presentisme', der ofte sniger sig ind med begreber som transnationalisme eller globalisering, der illuderer at karakterisere tiden lige præcis 'nu'. Dette greb risikerer følgelig at ignorere den lange forhistorie islam og andre globalt ekspansive verdensreligioner har haft i århundreder (Bubandt 2001). 
Hvorfor 'rejser' nogle religioner tilsyneladende bedre end andre? For at besvare dette spørgsmål, må man se på de specifikke betingelser der er for religioners udbredelse - og her er et studie af de transnationale sociale felter relevant. Men transnationalisering af en religion kræver, som Thomas Csordas (2009) fremhæver, også noget af religionen selv: for at en religion kan udebredes i stor skala skal den have en 'bærbar praksis' og en 'overførbar besked' (ibid.: 4-5). En succesfuld transnationalisering af islam (eller en hvilken som helst anden religion) kræver desuden at religiøse praksisser og ideer kan 'få et lift' via et transportmiddel. Her opremser Csordas henholdsvis missionsvirksomhed, medier, migration og mobilitet som de mest iøjnefaldende (ibid.: 5-6). Alle fem artikler i dette temanummer illustrerer hvordan disse sådanne 'fartøjer' bidrager til transnationaliseringen af islam fx i kraft af virtuelle læringsfællesskaber, rejsende imamer eller migranters fortsatte tilknytning til religiøse ideer og praksisser fra deres første hjemland.

I temanummerets første artikel anvender Lasse Lindekilde karikaturkrisen og det arabiske forår til at pege på, hvad han kalder 'transnational aktivisme'. Han diskuterer i hvilken grad transnational mobilisering via nye sociale medier reelt har det revolutionære potentiale til at give mere eller mindre undertrykte minoriteter en stemme, som man ofte umiddelbart tillægger dem. Med udgangspunkt i en analyse af udviklingen af karikatur-krisen i og udenfor Danmark beskriver Lindekilde hvad han kalder en 'boomerang effekt', hvor den meget omdiskuterede imam-delegation var et forsøg på at skalere en lokal konflikt fra 'lille Danmark' til at adressere en bredere offentlighed i andre dele af verden, herunder måske særligt i Mellemøsten. Optrapningen gav imidlertid bagslag og viste sig på sigt at svække sagen og skade omdømme og troværdighed blandt de personer, der deltog i delegationen. På denne baggrund reflekterer Lindekilde over de sociale mediers frigørende potentiale og betydning i det arabiske forår. Artiklen viser, at selvom imamdelegationen agerede $i$ et transnationalt socialt felt og appellerede til en bredere offentlighed, gav den transnationale mobilisering bagslag for dem i den lokale danske kontekst. Eksemplet illustrerer globaliseringens uforudsigelige dynamikker, for ikke bare var delegationens effekt i Danmark utilsigtet; det var dens effekt i resten af verden også, da rygter om tegningerne spredte sig i ukontrollable netværk medieret af nye sociale medier og motiverede demonstrationer og uroligheder i en række lande, som for eksempel Syrien, Pakistan og Indonesien. 
Den lokale nationale kontekst spiller ligeledes en central rolle i Kirstine Sinclair sammenlignende studie af den internationale islamistiske organisation Hizb ut-Tharir's afdelinger i henholdsvis Storbritannien og Danmark. Selvom organisationen slår sig op på at være global og på at arbejde ideologisk for Khalifatets genindførelse, så viser Sinclairs studie af to nationale afdelinger, at organisationen i stigende grad er lokalt forankret og måske i stigende grad begynder at være mere nationalt orienteret, hvilket blandt andet kommer til udtryk ved, at man skifter navn til Hizb utTharir Britain (HTB). I kraft af medlemmernes forankring i nationalstater med vidt forskellige livsbetingelser forekommer det svært (måske endda lidet ønskværdigt) at finde fælles fodslag om en enstemmig vision for organisationen. Artiklen illustrerer, hvordan der kan være forskel mellem transnational islam, her i betydningen af en international organisation med et fælles politisk sigte, og de konkrete udmøntninger disse antager lokalt. Internettet spiller en væsentlig rolle i udbredelse og etablering af den globale organisation, men virker måske på den lange bane direkte modsat, i det internetsiderne kommer til at adressere et lokalt publikum.

Kasper Mathiesens artikel viser ligeledes, hvordan nye medier anvendes i udbredelsen af islam. Med afsæt i det, Mathiesen kalder en neo-traditionalistisk sufi orden, fokuserer analysen på de 'selvets teknologier', der knytter sig til religiøs praksis i bâ'alawiyya-traditionen, som den formidles i de internationale undervisningsforløb, denne sufi-gruppe tilbyder. Kursernes succes afhænger blandt andet af deres evne til at kondensere bâ'alawiyya-traditionens religiøse indhold i en række 'bærbare' praksisser eller rituelle teknologier og en 'overførbar' besked, der især handler om den rette omgang med selvet. Selvet er således både et vigtigt udgangspunkt for sufismens ideer om den korrekte tilbedelse af Allah og for senmodernismens ideer om refleksion og det succesfulde liv. Mathiesen viser, hvordan universitetet i Tarîm, deltagelse i virtuelle læringsfællesskaber samt sommerskoler for dedikerede murids fra hele verden nærmest giver ordenen en centripetal kraft mod centret omkring shaykh al-Habîb 'Umar bin Hafîz samt en centrifugal kraft i sin udbredelse og missionering, hvor dedikerede studerende gennem selvets teknologier skal agere gode eksempler og derigennem øve indflydelse på muslimske brødre og søstre og de lokale sammenhænge, de lever i rundt om i verden.

Som allerede påpeget med Ralph Grillo overfor, er forestillingen om ummaen per definition transnational (måske før-national), idet den samler muslimer i hele verden trods divergerende religiøse retninger og på tværs af etnisk pluralisme, sprogforskelle, landegrænser og kontinenter. 
Baseret på en beskrivelse af en række arabisksprogede fredags khutba'er givet af forskellige imamer i Det Islamiske Trossamfund i København, analyserer Andreas Lysholt Mathiasen de udlægninger af ummaen der mobiliseres. Et gennemgående tema er, hvordan ungdommen, som den nye generation, spiller en signifikant rolle for ummaen blandt arabiske muslimer, både i vesten (i dette tilfælde Danmark) og for revolterne i det arabiske forår. Selvom forestillinger om ummaen henviser til et overnationalt muslimsk fællesskab, viser Lysholt Mathiasens analyse, hvordan der i de senere år er sket et konkret skifte i Det Islamiske Trossamfunds generelle standpunkt: hvor der tidligere var fokus på at levere et islamistisk politisk indhold gennem khutba'en, synes det nu vigtigt at præsentere et mere klassisk salafistisk indhold med fokus på ritualer og moralske handlinger.

I den sidste artikel tager Mikkel Rytter afsæt i pakistanske migrantfamilier og diskuterer, hvordan og hvorfor nogle af disse tilsyneladende, trods en markant social, økonomisk og uddannelsesmæssig mobilitet gennem deres fyrre år i Danmark, har mistanke om, at de er ramt af kala jaddu (trolddom), der udspringer fra Pakistan. Sådanne forestillinger er integreret del af den Barelvi-tradition og udlægning af islam, der er fremtrædende i store dele af Punjab. Migrantfamilier indhentes så at sige af fortiden. Modtræk mod okkulte angreb erhverves ofte i Pakistan af en pir (shaykh), der kan tilvejebringe religiøse teknologier i form af amuletter og bønner. Disse kan bruges som værn mod de dårligdomme, der trænger sig på. Det transnationale sociale felt migranterne lever og agerer i har således nogle transcendente dimensioner. Endelig diskuterer Rytter, i hvilket omfang verserende mistanker om okkulte angreb knytter sig til den spirende ontologiske usikkerhed, der dels er resultatet af en migrantfamilieinstitution i forandring og dels af den massive sikkerhedsliggørelse af islam og muslimer, der har taget fart i Danmark siden 2001.

Samlet set viser særnummerets fem artikler, hvordan islam ikke blot manifesteres som religiøs tro, praksis og fællesskaber på tværs af lande grænser, men også hvordan religionen islam i høj grad udgør en global drivkraft og dynamik, der har fået endnu mere signifikans med udbredelsen af diverse sociale og trykte medier, igennem intensiveringen af tele-kommunikation, og i kraft af den stigende globale mobilitet der er gjort mulig af stadigt billigere flybilletter. Alle fem artikler viser dog samtidigt også (i varierende grad), at den lokale nationale kontekst fortsat spiller en stor rolle for hvordan islam fortolkes og praktiseres af muslimer. 
God læselyst,

Redaktionen

Artiklerne i dette nummer af tidsskrift for islamforskning blev første gang prcesenteret på et forskningsseminar om 'Muslimer i transnationalitet' afholdt i januar 2011 på Aarhus Universitet, arrangeret af 'FIFO - foreningen for islamforskning' i samarbejde med forskningsprogrammet 'Sufism and Transnational Spirituality' (www.sufism.au.dk).

\section{Referencer}

Beck, Ulrik, 2002: “The Terrorist Threat: World Risk Society Revisited”, in Theory, Culture \& Society 19(4): 39-55.

Berger, Peter, 1999: The Desecularization of the World: Resurgent Religion and World Politics, Washington, Ethics and Policy Center.

Bubandt, Nils, 2001: 'Efter globalisering? Nogle antropologiske overvejelser', Jyske Historiker 9495: $42-70$.

Casanova, José, 1994: Public Religions in the Modern World. Chicago, The University of Chicago Press.

Csordas, Thomas, 2009: 'Introduction: Modalities of Transnational Transcendence', i T. Csordas (red.): Transnational Transcendence. Essays on Religion and Globalization, Berkeley, University of California Press, 1-29.

Gluckman, Max, 2006 [1961]: 'Ethnographic Data in British Social Anthropology', I Evans, T.M.S og D. Handelman (red): The Manchester School: Practice and Ethnographic Praxis in Anthropology, New York og Oxford, Berghahn Books, 13-22.

Grillo, Ralph, 2004: 'Islam and Transnationalism', Journal of Ethnic and Migration Studies 30(5): 861-878. 
Habermas, Jurgen, 2002: Religion and Rationality: Essays on Reason, God and Modernity, Cambridge, Polity Press.

Levitt, Peggy og Nina Glick Schiller, 2004: 'Conceptualizing Simultaneity: A translocal social field perspective on society', International Migration Review 38(145): 595-629.

Robbins, Joel, 2004: 'The Globalization of Pentecostal and Charismatic Christianity', Annual Review of Anthropology 33: 117-143.

Wimmer, Andreas og Nina Glick Schiller, 2003: 'Methodological Nationalism, the social sciences, and the study of Migration: an Essay in Historical Epistemology', International Migration Review, 37(3): 576-610. 